\title{
Literature-Based Instruction: A Worthwhile Approach for the Mastery of a Second Language
}

\author{
ÇAĞRI TUĞRUL MART \\ Department of Languages, \\ Ishik University, Iraq \\ cagri.mart@tiu.edu.iq
}

\begin{abstract}
Literature has the potential to encourage learners to become cognisant of patterns and linguistic features of the language because it creates an environment where the applications of the language can function. A growing body of literature has supported the incorporation of literature in second language teaching on the grounds that literature signifies a wide range of accurate use of the language features that paves the way for learning the target language. The present paper attempted to explore the perceptions of learners about welcoming literature in the language classroom for extending language use. The data presented in this study are from interviews. 60 senioryear ELT students were interviewed to reveal their attitudes towards the inclusion of literature into language teaching. Although a small number of the participants questioned the effectiveness of literature, a large number of the participants enumerated several reasons for the inclusion of literature in language learning. The results of the interview highlight the premise that the incorporation of literature into language teaching is shown to be worthwhile for offering a new language learning experience, creating a medium to promote engagement, providing an avenue for coming to good terms with personal development, building an ethos to enhance accuracy and fluency, and constituting ideal occasions to develop learner autonomy.
\end{abstract}

Keywords: literature; language learning; incorporation; language awareness; language development

\section{INTRODUCTION}

An ample amount of research evolved around the inclusion of literature in second language teaching to provide some of the strongest rationales for language acquisition (Collie \& Slater 1987; Duff \& Maley, 1990; Lasagabaster, 1999; Weist, 2004; Barrette et al., 2010; Nance, 2010; Bloemert et al., 2017; Viana \& Zyngier, 2019; Tsang et al., 2020). The widespread idea is that language and literature are mutually supporting experiences and they can work in tandem to progress to advanced-level language competencies; thus, the inclusion of literary texts in language instruction is an essential grounding for arming learners with not only linguistic knowledge but also cultural knowledge.

Language-literature division was described as "a recipe for disaster" in 1989 (James, 1989, p.81). Literature was considered complex and inaccessible, thus, the use of literary texts was eliminated from language classes (Mart, 2018a). Within the tradition of foreign language teaching, the function of literature has changed, and it has been raised as an influential tool for the last two decades; consequently, in EFL instruction, literature has been adopted as a valuable strategy. Literature is considered as "an ally of language" (Brumfit \& Carter, 1986, p.1) and it creates an environment where the applications of the language can function. Literary texts are treated as learning resources like any other classroom materials (Isaac, 2002). This paper aims to show the value of introducing literature at university level and attempts to determine whether plunging learners into rich exposure of literature gives a basis for language proficiency development. Informal interviews were carried out with 60 EFL senior-year students to reveal their perceptions towards the inclusion of literature in language learning. 


\section{INTEGRATING LITERATURE INTO THE LANGUAGE CLASSROOM}

Literature has the potential to maximise learners' opportunities to become proficient in the target language. Collie and Slater (1987) demonstrate a move toward the use of literature in the language classroom because of its merits as a valuable, authentic material in which learners can process real language in context for cultural enrichment, language development, and personal growth. First, compared with informational materials, authentic materials are more suitable and valuable to language learning. Furthermore, literary texts, as they are intended for native speakers, are good models for language learners to be acquainted with language forms and conventions (Ur, 1996; Mart, 2017). Second, cultural goals are achieved through broadening learners' horizons by introducing literature masterpieces as an educative experience. Literary texts have the advantage of improving learners' cultural awareness by allowing them to discover other countries and their people. Third, "rich exposure to authentic English" (Tomlinson, 1985, p.9) and "real language, such as that found in literature" (Whiteson \& Horovitz, 1998, p.xiv) increase familiarity with the language and enhances linguistic accuracy. Finally, the use of literature introduces critical thinking to learners of language as well as intellectual development. Literature is full of real-life language examples in different situations; hence, literature readers are at an advantage to deepen their awareness of social factors. Literary encounter allows learners to develop their understanding and appreciation of cultural and ideological differences of societies.

In attempting to support their argument of incorporating literature into language teaching, Duff and Maley (1990) attest that literature attracts readers in three domains: linguistic, methodological and motivational. Literature is comprised of a wide range of vocabulary and a variety of grammatical structures and dialogues in which ideas are connected in numerous ways. Linguistically, providing learners with valuable authentic materials allows them to explore the forms and communicative functions in the target language. Literature draws learners' attention to the links between language and communicative intent (Walther, 2007; Nguyen, 2014) because literature involves "formation and function of sentences, variety of possible structures, and different ways of connecting ideas" (Collie \& Slater, 1987, p.5). Bassnett and Grundy (1993) make an excellent point in noting that "literature is a high point of language usage" (p. 7). With this aspect, literature is an important element for readers to engage in linguistic forms and communicative functions (Mart, 2019a; Mart, 2019b). Literary texts embed conversational excerpts (Durant, 1995); to put the matter somewhat differently, they have communicative value. Hadaway et al. (2002) contend that literature contextualises language; literature provides an ideal context to acquire profound knowledge of language. It facilitates access to a variety of linguistic items. Literature, therefore, can offer an "acquisitionrich environment" (Ghosn, 2002, p.175). Similarly, Shepin (2019) sheds light on the power of literature for language acquisition. Methodologically, literature makes learners sensitive to the reading process. Motivationally, literature is viewed as a motivational material (Elliot, 1990), wherein the reader is placed in authentic and meaningful contexts to decode literary texts. During meaning construction, learners engage in the process of language acquisition and become enthusiastic to discover the plots of the story and experiences of characters. Literature is seen as a tool "to stimulate the imagination of students, to develop their critical abilities, and to increase their emotional awareness" (Lazar, 1993, p.19).

Lasagabaster (1999) advocates the incorporation of literature into foreign language teaching. He argues that literature is an enormous source of cultural enrichment, and the potentiality of literature can develop cross-cultural awareness. It is worth considering that the development of communicative competence requires cultural competence (Byram \& Morgan, 1994). Literary texts are not intended for language teaching. Instead, it arouses readers to deepen and intensify understanding. For that reason, they meet the standards of authenticity. 
There is no blinking at the fact that language learners are exposed to a great wealth of comprehensible input by means of literature that fosters language learning. Literary texts are interpreted differently by learners; hence, the utilisation of literature boosts the interpreting skills of language learners. Kramsch (1994) highlights that "speakers and writers make choices that are not predictable and codifiable" (p.130) bearing in mind the support of literary works on the development of interpretative skills. Also, literature helps in the enhancement of learners' imagination and extends personal experience.

Shanahan (1997) refutes the objections to language learning through literature and underlines three aspects of literature which are conducive to the learning of language: a) literature is laden with divergent and evocative materials, b) these materials are engaged by learners and energize language learning, c) literature embodies strong undercurrents of the time and place in which it was written. Alvstad and Castro (2009) defend the idea of giving priority to literary texts within language study and lay out two arguments for incorporating literature in the curricula of foreign languages. The first argument is the pivotal role of literature in the development of linguistic competences and the second argument is the potency of literature in furnishing knowledge about foreign cultures. In both arguments, they recommended that literature be integrated into language learning classes in the spirit of language proficiency development.

A growing body of literature investigated the integration of literature and language learning and they offered a number of reasons why language learners are at an advantage when literature is introduced in the language classroom. To put the matter at its most basic level, literature supports conducive language learning environments and provides a springboard for language acquisition processes. The use of literature in language learning is a useful resource for the enhancement of vocabulary, grammatical accuracy, language skills, speaking fluency, reading proficiency, personal development, thinking skills, and cultural awareness.

\section{WHEN SHOULD LITERATURE BE INTRODUCED TO LANGUAGE LEARNERS?}

Literature that foregrounds aesthetic intent is a complex enterprise to teach. Frantzen (2001) advocates the use of literature at all levels in foreign language programmes because literature provides "contexts for meaningful classroom dialogues" (p.109). Context is "the physical situation or setting in which any text-spoken or written-occurs" (Gajdusek, 1988, p.230). Context-rich learning encourages learners to ascertain common difficulties by experientially investing in the texts. Weist (2004) sheds light on the power of literature with lower-level learners for skill acquisition and she concludes that the use of literary texts in beginning-level language courses could help language practice and reading comprehension. Literary texts with lower-level learners provide excellent conditions for a basic understanding of the context, development of thinking skills as well as improvement of language skills. The inclusion of literary texts in language teaching programs across intermediate level language learners stimulates language development and raises language awareness. Literary texts with advanced learners can be used to develop higher-order critical skills including complex judgmental skills such as critical thinking and problem-solving.

Exploration of literature in foreign language classroom at all levels of instruction offers "more communicative and interactive" (Gajdusek, 1988, p.228) language classes. A perusal of literary texts in language teaching generates language practice, reading comprehension and the appreciation of aesthetic qualities at the beginning levels. The study of literature in introductory-level courses provides an occasion for the exploration of functions of language in context. Thus, learners are able to take advantage of the perceived connections between language and communication. Conversely, the aims for literary study within advanced-level 
classes include engaging learners in reading practices as well as discussing issues and situations that are explored in literary texts, and the presentation of literary concepts. The wider use of literature can be profitable to develop grammatical skills (Gajdusek \& van Dommelen, 1987), to decode the meaning of unfamiliar words, and to practice talking (Enright \& McCloskey, 1985; Blikstad-Balas et al., 2018). It should be noted that literature exhibits "extraordinary growth in vocabulary" (Spack, 1985, p.721), and its communicative potential. With this in mind, the exposure to literary texts at all levels provides language learners an avenue to master the language (Mart, 2018b; Torrano-Guillamon et al., 2019; Gabrielsen et al., 2019).

Literary texts of a high caliber affect accessibility and comprehensibility. Indeed, unless learners sufficiently penetrate the text, they cannot make general sense of it. Inaccessible texts containing difficult vocabulary and sophisticated syntactical patterns constitute sources of frustration and become useless for language learners (Schulz, 1981). Learners who are unprepared and do not have an appropriate level of linguistic competency may find it difficult to comprehend literature. Needless to say, it is important to examine texts in terms of the level of difficulty before presenting them to the intended learners. A common belief in the teaching of literature is that literary texts of medium difficulty familiarises learners with the language of the text. By focusing on literary texts, issues on text accessibility among learners at all levels may be addressed. The present study addresses the following research questions:

1) Can literature and language learning work in tandem to enhance proficiency in the target language?

2) What kind of benefits can learners reap from the inclusion of literary texts in language learning?

\section{RESEARCH CONTEXT}

The current study was conducted to gain perspectives on the participants' encounter with literature in the language classroom. The participants, aged between 19 and 26, included 60 senior-year ELT students ( 35 females, 25 males) at a university in Iraq. All fourth-year students in the department volunteered to participate in the study, and they met three (3) hours per week in literature classes. Lord of the Flies (2003) by William Golding was chosen for the study due to its accessible language and themes. Themes related to civilization and savagery within the selected text gave participants frequent opportunities to articulate their interpretations. Over a period of eight (8) weeks, the participants read the novel and engaged in a process of discovery to identify the setting, character and plot through deciphering the meanings of unknown words and perceiving the characteristics of target structures for classroom discussions.

Participants' motivation and attitudes about classroom activities are not explicitly observable. With the help of interviews, researchers accessed their inner perceptions and collected the data. Semi-structured interviews were conducted with all the participants to gain perspectives about their experiences with literature. Interviews were audio-taped and later transcribed. Intonation and length of pauses were ignored, and the focus was on what was said by the participants. The one-on-one interview with each participant outside the class lasted 10 to 15 minutes (see Appendix for the interview questions). Student interview was an important component of data gathering to determine their views of the application of literary texts for the development of language skills. Audio-taped interviews were carefully analysed to label relevant phrases and sentences, and these were then coded by three researchers into relevant themes or concepts associated with literature. The researcher worked closely with his colleagues to analyse and categorise the data. Also, member checking was used for verification whereby results were returned to participants to review for accuracy and validity of the work (Doyle, 2007). The broad analysis of these interviews yielded important information about the 
perceptions of participants regarding the role of literature in the development of language proficiency.

\section{INTERVIEW RESULTS AND DISCUSSION}

TABLE 1. Data emerging from the analysis of the participants' experiences with literature

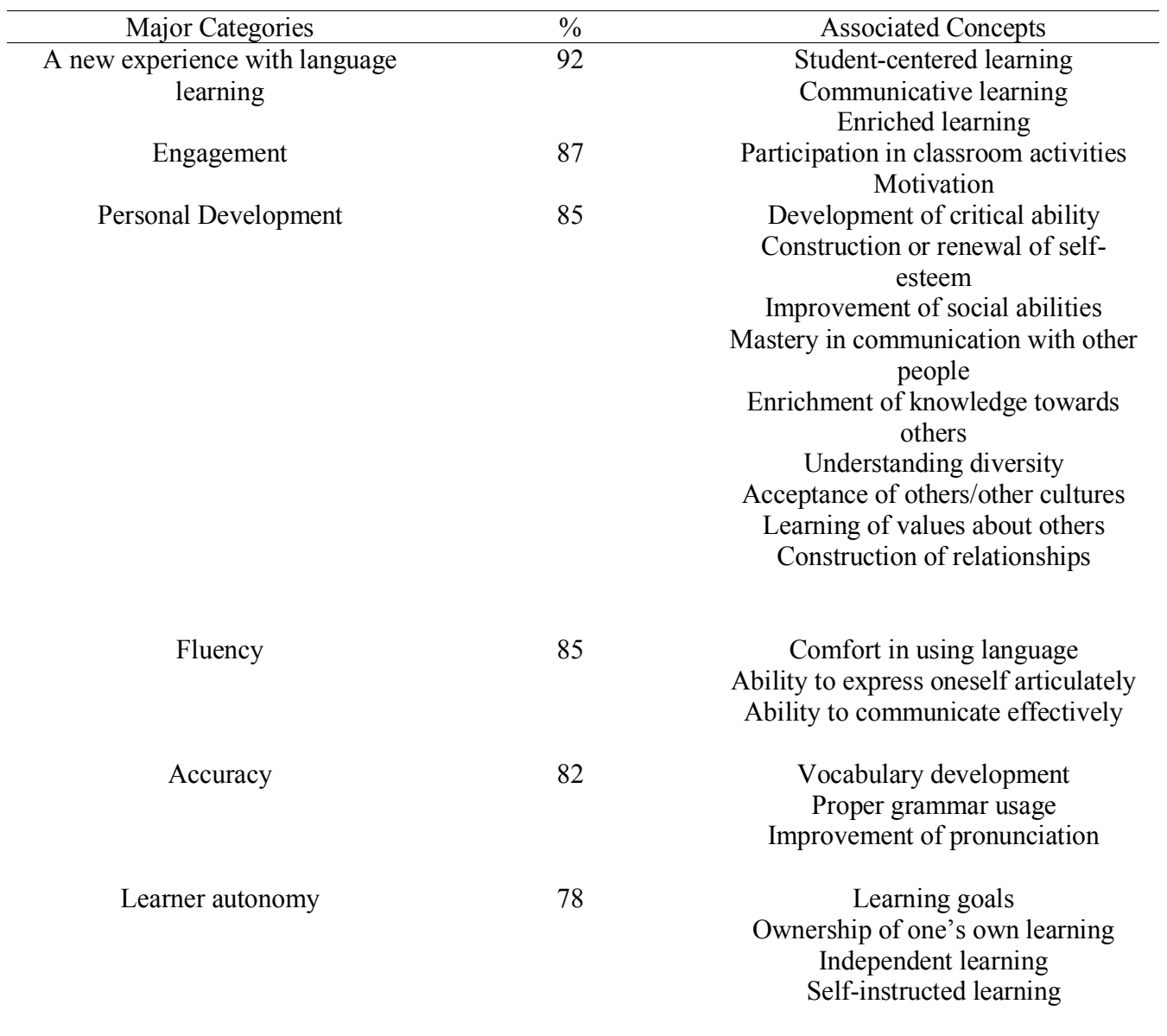

$* \mathrm{~N}=60$

Table 1 illustrates the major categories and associated concepts found in the interview. The most salient findings concerning language learning with literature are three-pronged, firstly, a new experience, secondly, engagement, and thirdly, personal development. The frequency of interviews indicates that the participants who took part in this study found discussions a new experience in language learning, as well as highlighted the role of discussions in being a motivating factor for them to engage in discussions. The table also shows that the participants considered literature as a catalyst for personal development. 
3L: Language, Linguistics, Literature ${ }^{\circledR}$ The Southeast Asian Journal of English Language Studies Vol 27(2), June 2021 http://doi.org/10.17576/3L-2021-2702-04

TABLE 2. Negative opinions expressed by the participants about the integration of literature in language teaching

\begin{tabular}{|c|c|c|}
\hline Major Categories & $\%$ & Reasons \\
\hline $\begin{array}{l}\text { A new experience with language } \\
\text { learning }\end{array}$ & 8 & Preference for traditional methods \\
\hline Engagement & $\begin{array}{l}8 \\
5\end{array}$ & $\begin{array}{c}\text { The discussions went by quickly } \\
\text { Being unprepared }\end{array}$ \\
\hline Personal Development & $\begin{array}{l}9 \\
6\end{array}$ & $\begin{array}{c}\text { Lack of focus on values for personal } \\
\text { development } \\
\text { The book was not inspiring }\end{array}$ \\
\hline Fluency & $\begin{array}{l}7 \\
5 \\
3\end{array}$ & $\begin{array}{c}\text { Anxiety } \\
\text { Lack of subject matter } \\
\text { The domination of quick learners }\end{array}$ \\
\hline Accuracy & $\begin{array}{l}8 \\
6 \\
4\end{array}$ & $\begin{array}{l}\text { Limited vocabulary knowledge } \\
\text { Bad grammar habits } \\
\text { Insufficient opportunities to improve } \\
\text { pronunciation }\end{array}$ \\
\hline Learner autonomy & $\begin{array}{c}12 \\
5 \\
5\end{array}$ & $\begin{array}{c}\text { Preference for different resources to } \\
\text { promote language proficiency } \\
\text { Lack of motivation } \\
\text { Pacing }\end{array}$ \\
\hline
\end{tabular}

Table 2 demonstrates the negative opinions stated by the participants about the inclusion of literature in language teaching. The major categories and related reasons found in the interview are displayed in the table.

\section{A NEW EXPERIENCE WITH LANGUAGE LEARNING}

The use of literature for language proficiency development was considered as a new experience for a large number of participants who took part in this study. The findings revealed that the combination of form and meaning through interactions in the classroom discussions of literature received increasing attention from them. The fact that the participants had substantial opportunities to develop their accuracy and fluency simultaneously raised their levels of attention to classroom discussions of literature. Some of the participants stated:

I used to learn English by memorizing grammar and vocabulary which did not help me with my practice. But the use of literature discussions not only helped me with my linguistic competence but also communicative competence development (Participant 9).

I never thought that language learning and teaching would be interesting by speaking in the classroom. Literature discussions showed that language learning could be conducted in a useful and enjoyable way (Participant 13).

I remember studying grammar, vocabulary and communication courses separately. With classroom discussions of literature, we combined them all. It was easier and more fun to learn (Participant 5).

A small number of the participants expressed negative opinions about the inclusion of literature in language teaching. These participants stated that they learned better when methods based on memorization were employed in language classes.

I always learned English by memorization. I had to memorize vocabulary and grammar to be successful. Our teachers never created an environment to speak in English (Participant 8).

It was not easy for me to participate in the classroom discussions of literature because it was a totally new experience for me. Our teachers explained to us everything in our native language (Participant 10). 


\title{
ENGAGEMENT
}

Classroom discussions of literature provide a venue for learners to engage in lively discussions about the literary texts that they have read. Creating classroom literacy environment boosts engagement and stimulates dialogic talk in which learners express their interpretations of literary texts. Holding classroom discussions is an optimal setting for learners to engage in learning and switching their roles from knowledge-consumers to knowledge-constructors (Nystrand, 2006). Literature discussions spawn engagement and create a space for participants in which they verbalize multiple interpretations that initiate language learning. The great majority of the participants in this study reported increased engagement as an important aspect of classroom discussions of literature. Some of the participants stated:

\begin{abstract}
Classroom discussions increased my willingness to engage in learning. Observing others sharing their ideas triggered my interest and incited me to take participate in discussions (Participant 3 ).

I was energised by literature discussions and I found the discussions totally engaging. I took visible delight in participating in literature discussions (Participant 15).

I always tried to show involvement in literature discussions. I never thought of withdrawing from learning opportunities provided by the discussions (Participant 12).
\end{abstract}

A much lower percentage did not seem to believe in the potency of literature discussions to foster engagement in learning. The participants reported two obstacles that hindered their engagement in the discussions. They stated that the quick pace of discussions and unpreparedness impeded them from immersing in classroom discussions.

\begin{abstract}
I was not always prepared; therefore, I was unable to pay attention in the class, and of course, it hindered my involvement in the content (Participant 11).

The discussions went by quickly. I could not immerse myself in classroom discussions. Before I understood the story, they were talking about another topic (Participant 7).
\end{abstract}

\section{PERSONAL DEVELOPMENT}

Literature is viewed as an excellent medium to develop critical abilities, trigger imagination and enhance emotional development (Lazar, 1993). Literature encourages learners to take advantage of improving cultural awareness and intellectual development (Dwyarie \& Tjahjani, 2019). Literary encounter allows learners to become aware of social factors around the world. Learners deepen their understanding of the world while reading literature (Dewi, 2019). They perceive ideological and cultural differences between people and develop interpersonal and intercultural attitudes. Literature is an inviting way for learners to promote their personal development. Many participants in this study regarded literature as a catalyst for personal development because of its supportive role in the development of self-esteem, social ability, communication, and understanding of other cultures. These findings concur with the findings of Alvstad and Castro (2009). Some of the participants expressed that:

\footnotetext{
I always put myself in the characters' place and asked myself what I would do if I were him or her? I always tried to imagine how they felt (Participant 15).

I read about other people, other cultures. I know something about their values, their cultures. I think it is worth learning about other people and cultures because we have a lot in common

(Participant 6).

When I read the story, I thought clearly what the character had to do or what decisions he had to take to solve the problems (Participant 18).
}

A small number of the participants stated negative opinions and explained that their focus was on understanding the text rather than the values in it. Also, they expressed that the reading material did not motivate them to learn about other people and cultures. For that reason, literature did not help them with personal development: 
My major goal was to read and understand the text. I just focused on the characters and the story to say something in discussions (Participant 35).

The book chosen for the classes was not inspiring. I could almost found nothing to learn about life, other people and cultures. I could not empathise with the characters (Participant 27).

\section{FLUENCY}

Fluency depends on quick access to syntactic and lexical devices of a language for an effective operation of its system (Nation, 1989). The flow and speed of language production is a prerequisite to use the language appropriately and efficiently. Accuracy and fluency are pivotal factors to communicative techniques. That language accuracy is performed fluently is essential to language learning. The data reveals a slight difference between participants' assessment of accuracy and fluency; however, the preeminence of fluency is apparent. In other words, the number of participants who reported that literature discussions have boundless possibilities to improve their fluency is more than the number of those who reported that literature discussions open up infinite possibilities to develop their accuracy. Some of the participants stated that:

\footnotetext{
I developed fluency in literature discussions because they pushed me towards the delivery of a message. Transmitting ideas in discussions promoted my fluency (Participant 53).

That my attention was communicating the message with other students in literature discussions helped me develop fluency (Participant 41).

I was very interested in the discussions. They always gave me the desire to communicate in classes. Communicating with the teacher and my peers enabled me to speak the language fluently (Participant 38).
}

A few participants disagreed about the impact of literature on fluency development. The factors that inhibited their fluency were stress and anxiety, lack of subject matter, and the domination of quick learners.

\footnotetext{
It is hard to communicate when you are overwhelmed with anxiety. Although I found literature discussions to be very useful in developing language proficiency, I could not reduce my stress and anxiety in the classroom (Participant 22).

I was discouraged because in the discussions the strong learners dominated the slow learners. I was shy and intimated so I couldn't express my thoughts (Participant 36).
}

\section{ACCURACY}

It is worth noting that accuracy determines the success of language learners. Literary texts offer a motivating medium for language learning through engaging learners in linguistic forms and communicative functions. Learners delve into a variety of grammatical structures and vocabulary by means of literary texts that lead to an extensive range of enrichment in linguistic knowledge. Literature enriches the fertile ground to discover grammatical, lexical or discoursal categories that can be used as a springboard for language acquisition (Lazar, 1993). The provision of adequate linguistic resources through literature is associated with linguistic accuracy. The acquisition of grammatical accuracy provides clear advantages to develop native-like abilities in written or oral language proficiency (Millard, 2000; Nusrat et al., 2019). The great majority of the participants reported that literature is a valuable input-rich source to improve accuracy. These findings are consistent with those of Hoecherl-Alden (2006) who argues that the richness of literature forms the basis for comprehensible and creative language use. Some of the participants stated that:

Literature helped me enhance linguistic accuracy and classroom discussions were ideal for practicing grammatical structures. I had a lot of opportunities to see how sentences occur in texts (Participant 53). Literature helped me with the acquisition of linguistic elements and in literature discussions, I was immersed in the practice of these features (Participant 32). 
Literature provided me a great number of opportunities to develop accuracy. I saw how linguistic elements are used in context (Participant 47).

A small percentage of the participants stated that the lack of adequate vocabulary knowledge, bad grammar habits, and insufficient opportunities to enhance pronunciation in literature discussions impeded their grammatical accuracy.

\footnotetext{
I was unable to express my ideas effectively because I didn't know enough vocabulary to participate in the classroom discussions and utter my ideas (Participant 57).

I now realize that some of the grammatical rules I learned when I was in high school were not exactly accurate. It is now difficult for me to correct the grammatical errors (Participant 7).
}

\section{LEARNER AUTONOMY}

The concept of learner autonomy has come to be used for situations in which learners take control over their own learning and study entirely on their own (Benson \& Voller, 1997). Similarly, the idea of learner autonomy consists of independent action and decision-making (Little, 1991). In a way, learner autonomy is associated with a shift from directed teaching to self-instructed learning (Little, 2007). Autonomous learners are motivated and can independently set their goals. Their capacity to oversee their own learning enables them to take an active role in their own learning process. Once autonomous learning is achieved, learners can avail themselves of learning opportunities without teacher dependence. Little (2007) argues that the promotion of learner autonomy in language learning is determined by learner involvement, learner reflection, and appropriate target language use. Literature and literature discussions in the learning process engage learners to act responsibly and share responsibilities, be stimulated to think critically as learners are provided with an ideal language learning in which the target language is used as the principal medium. In this study, more than half of the participants viewed literature reading and literature discussions as useful means of selfinstructed learning. This study revealed findings similar to those of Lasagabaster (1999) who considers literature as a potential source to promote learner autonomy. The participants reported that literature motivated them to set goals independently for language proficiency and allowed them to control their learning:

\footnotetext{
Classroom discussions allowed me to understand why I had to learn English effectively. It enabled me to discover my weaknesses. I have to review my learning (Participant 20).

Literature reading and literature discussions showed me that I need to increase my language skills. It is important for me now to continue my learning outside the classroom (Participant 55).

One of the biggest challenges that I experience while learning English is not deciding what to study. But classroom discussions of literature have been very useful for me as they showed me how to control my own learning (Participant 46).
}

A small portion of the participants stated that the preference for different sources for language learning, lack of motivation, and the quick pace of the classes were factors that prevented them from developing learner autonomy.

I prefer online English learning sources to improve my language skills. It is much better than reading. (Participant 43)

Reading requires motivation. It is not easy to develop a reading habit. And when I do not understand what I read I give up. (Participant 33). 


\section{CONCLUSION}

Literature has been raised as an influential tool in the language classroom for language proficiency development. Literature offers an ideal medium for language learners because it includes a wide range of vocabulary and a variety of grammatical structures and dialogues which help them with the development of language awareness as well as communicative competence. The use of literature in the language classroom provides linguistic, methodological, and motivational benefits for learners; for that reason, it should be introduced at all levels. The wider use of literature in language curriculum with learners from all levels stimulates language development. The results of the interview demonstrated that the participants in this study welcomed the incorporation of literature because the use of literature provided clear advantages to make better progress in language proficiency development. They accrued quite tangible benefits from exposure to literature. For them, literature was a new language learning experience and it was suitable to improve accuracy and fluency, promote engagement, enhance personal development and develop learner autonomy that enabled them to assume more responsibility to regulate their own learning. These arguments would be consistent with the findings of several prior studies which support the integration of literature into language teaching (Tatsuki, 2015; Nance, 2010; Bloemert et al., 2017; Viana \& Zyngier, 2019; Arboleda-Arboleda \& Castro-Garces, 2019). While the majority of the participants stated that they defend the merits of literature as a valuable source to extend language use, a much lower percentage seemed to believe otherwise. Preference for different resources to promote language proficiency, limited vocabulary knowledge, bad grammar habits, wrong choice of reading materials are the salient reasons why literature is not supported in language learning by a small number of the participants. Classroom discussions of literature were used in this study to make room for language proficiency; however, anxiety, the quick pace of the discussions and lack of focus on values in the reading materials were also some of the important factors that hinder learners' embracing of literature in the language classroom.

The number of participants was small to adequately determine the role of literature in the language classroom. The study was further limited by the material resource and the duration of the research. Thereby, the study calls for further investigation with a large sample size with culturally different participants to make a clear generalisation about the use of literature in language learning. Longitudinal studies are needed to have better insights into the effectiveness of literature on language development. The study used a novel, but further research is needed in which more materials from different literary genres could be used to reveal more accurate information about the benefits of using literature in language learning.

\section{REFERENCES}

Alvstad, C. \& Castro, A. (2009). Conceptions of literature in university language courses. The Modern Language Journal. 93(2), 170-184.

Arboleda-Arboleda, A. \& Castro-Garces, A.Y. (2019). Fostering language learning in the university EFL classroom through literature: A task-based approach. GIST - Education and Learning Research Journal. 19, 101-127. https://doi.org/10.26817/16925777.706

Barrette, C., Paesani, K. \& Vinall, K. (2010). Toward an integrated curriculum: Maximizing the use of target language literature. Foreign Language Annals. 43(2), 216-230. https://doi.org/10.1111/j.19449720.2010.01075.x

Bassnett, S. \& Grundy, P. (1993). Language through literature. London: Longman.

Benson, P. \& Voller, P. (1997). Autonomy and independence in language learning. London: Longman.

Blikstad-Balas, M., Roe, A. \& Klette, K. (2018). Opportunities to write: An exploration of student during language arts lessons in Norwegian lower secondary classrooms. Written Communication. 35(2), 119-154.

Bloemert, J., Paran, A., Jansen, E. \& van de Grift, W. (2017). Students' perspective on the benefits of EFL literature education. Language Learning Journal. 47(3), 1-14. https://doi.org/10.1080/09571736.2017.1298149

Brumfit, C.J. \& Carter, R.A. (1986). Literature and language teaching. Oxford: Oxford University Press. 
Byram, M. \& Morgan, C. (1994). Teaching-and-learning language-and-culture. Clevedon: Multilingual Matters. Collie, J. \& Slater, S. (1987). Literature in the language classroom: A resource book of ideas and activities. Cambridge: Cambridge University Press.

Dewi, N. (2019). Cognition, conscience, and creativity: Multimedia-based literature teaching for pre-service teachers in Indonesia. 3L: The Southeast Asian Journal of English Language Studies. 25(2), 86-98.

Doyle, S. (2007). Member checking with older women: A framework for negotiating meaning. Healthcare for Women International. 28, 888-908. https://doi.org/10.1080/07399330701615325

Duff, A. \& Maley, A. (1990). Literature. Oxford: Oxford University Press.

Durant, A. (1995). Introduction to 'language through literature' approaches to teaching literature in English in L2 contexts. Middlesex University Research Repository. 291-311. Retrieved June 23, 2021 from https://eprints.mdx.ac.uk/8189/1/Interactive_methods_\%28Language_through_literature\%29.pdf

Dwyarie, R.D. \& Tjahjani, J. (2019). Intercultural concepts in place cliché by Jacques Godbout. 3L: The Southeast Asian Journal of English Language Studies. 25(3), 137-149.

Elliott, R. (1990). Encouraging reader-response to literature in ESL situations. ELT Journal. 44(3), 191-198.

Enright, D.S. \& McCloskey, M. L. (1985). Yes, talking!: Organizing the classroom to promote second language acquisition. TESOL Quarterly. 19, 431-453. https://doi.org/10.2307/3586272

Frantzen, D. (2001). Rethinking foreign language literature: Towards an integration of literature and language at all levels. In Scott, V. M. \& Tucker, H. (Eds.). SLA and the literature classroom: Fostering dialogues. Issues in language program direction: A series of annual volumes (pp. 109-130). Boston: Heinle \& Heinle.

Gabrielsen, I.L., Blikstad-Balas, M. \& Tengberg, M. (2019). The role of literature in the classroom. How and for what purposes do teachers in lower secondary school use literary texts? L1-Educational Studies in Language and Literature. 19, 1-32. https://doi.org/10.17239/L1ESLL2019.19.01.13

Gajdusek, L. (1988). Toward wider use of literature in ESL: Why and how. TESOL Quarterly. 22(2), $227-257$.

Gajdusek, L. \& van Dommelen, D. (1987). Exploring literature and teaching grammar in intermediate ESL. Paper presented at the 1987 CATESOL Conference, Pasadena, CA.

Ghosn, I. K. (2002). Four good reasons to use literature in primary school ELT. ELT Journal. 56(2), 172-179.

Golding, W. (2003). Lord of the flies. New York: Perigee.

Hadaway, N. L., Vardell, S. M. \& Young, T. A. (2002). Literature-based instruction with English language learners, $K-12$. Boston: Allyn and Bacon.

Hoecherl-Alden, G. (2006). Connecting language to content: Second language literature instruction at the intermediate level. Foreign Language Annals. 39(2), 244-254. https://doi.org/10.1111/j.19449720.2006.tb02264.x

Isaac, A. (2002). Opening up literary cloze. Language and Education. 16(1), 18-36. https://doi.org/10.1080/09500780208666817

James, D. (1989). Re-shaping the "college-level" curriculum: Problems and possibilities. In Lepke, H. S. (Ed.), Shaping the future: Challenges and opportunities (pp. 79-110). Middlebury: Northeast Conference Reports.

Kramsch, C. (1994). Context and culture in language teaching. Hong Kong: Oxford University Press.

Lasagabaster, D. (1999). Literary awareness in the foreign language classroom. Culture and Education. 11(2-3), 5-17. https://doi.org/10.1174/113564002320516740

Lazar, G. (1993). Literature and language teaching. Cambridge: CUP.

Little, D. (1991). Learner autonomy. 1. Definitions, issues and problems. Dublin: Authentik.

Little, D. (2007). Language learner autonomy: Some fundamental considerations revisited. Innovation in Language Learning and Teaching. 1(1), 14-29. https://doi.org/10.2167/illt040.0

Mart, Ç. T. (2017). Literary texts: A means to promote language proficiency of upper-intermediate level EFL students. Journal of Education in Black Sea Region. 2(2), 44-55.

Mart, Ç.T. (2018a). The contentious debate over the language literature division. Journal of Language and Cultural Education. 6(1), 117-127. https://doi.org/10.2478/jolace-2018-0008

Mart, Ç.T. (2018b). Literature in the language classroom: A recipe to maximize learning. L1 Educational Studies in Language and Literature. 18, 1-25. https://doi.org/10.17239/L1ESLL-2018.18.01.09

Mart, Ç.T. (2019a). Reflections on discussions of literature: A language learning environment to promote speaking skills. The Journal of Social Sciences Research. 5(4), 846-850. https://doi.org/10.32861/jssr.54.846.850

Mart, Ç.T. (2019b). A comparison of form-focused, content-based and mixed approaches to literature-based instruction to develop learners' speaking skills. Cogent Education. 6(1), 1-27. https://doi.org/10.1080/2331186X.2019.1660526

Millard, D.J. (2000). Form-focused instruction in communicative language teaching: Implications for grammar textbooks. TESL Canada Journal. 18(1), 47-57. https://doi.org/10.18806/tesl.v18i1.899

Nance, K. A. (2010). Teaching literature in the languages: Expanding the literary circle through student engagement. NJ: Prentice Hall. 
Nation, P. (1989). Improving speaking fluency. System. 17(3), 377-384.

Nguyen, H. T. T. (2014). How does an interactive approach to literary texts work in an English as a foreign language context? Learners' perspectives in close-up. Innovation in Language Learning and Teaching. 10(3), 171-189. https://doi.org/10.1080/17501229.2014.932361

Nusrat, A., Ashraf, F. \& Narcy-Combes, M.F. (2019). Effect of direct and indirect teacher feedback on accuracy of English writing: A Quasi-Experimental study among Pakistani undergraduate students. 3L: The Southeast Asian Journal of English Language Studies. 25(4), 84-98.

Nystrand, M. (2006). Research on the role of classroom discourse as it affects reading comprehension. Reading Research Quarterly. 46(8), 392-412.

Schulz, R.A. (1981). Literature and readability: Bridging the gap in foreign language reading. The Modern Language Journal. 65(1), 43-53.

Shanahan, D. (1997). Articulating the relationship between language, literature, and culture: Toward a new agenda for foreign language teaching and research. The Modern Language Journal. 81(2), 164-174.

Shepin, L. G. (2019). Making authentic literary texts relevant, meaningful, and fun in advanced beginner and intermediate Spanish-language classrooms. Hispania. 102(3), 313-318.

Spack, R. (1985). Literature, reading, writing, and ESL: Bridging the gaps. TESOL Quarterly. 19, 703-725.

Tatsuki, D. (2015). Repositioning literary texts in language teaching: The state of the art. Ann. Foreign Stud. 90, $1-13$.

Tomlinson, B. (1985, March 9). Language through literature and literature through language. EFL Gazette.

Torrano-Guillamon, L., Cascales-Martinez, A. \& Carillo-Garcia, E. (2019). Use of literature, resources and innovative methodologies in the English classroom. Porta Linguarum. 32, 53-70.

Tsang, A., Paran, A. \& Lau, W. (2020). The language and non-language benefits of literature in foreign language education: An exploratory study of learners' views. Language Teaching Research. 1-22. https://doi.org/10.1177/1362168820972345

Ur, P. (1996). A course in language teaching: Practice and theory. Cambridge: Cambridge University Press.

Walther, I. (2007). Ecological perspectives on language and literacy: Implications for foreign language instruction at the collegiate level. ADFL Bulletin. 38, 6-14.

Weist, V. D. (2004). Literature in lower-level courses: Making progress in both language and reading skills. Foreign Language Annals. 37(2), 209-223.

Whiteson, V. \& Horovitz, N. (1998). The Play's the thing. Cambridge: Cambridge University Press.

Viana, V. \& Zyngier, S. (2019). Language-literature integration in high-school EFL education: Investigating students' perspectives. Innovation in Language Learning and Teaching. 1-15. https://doi.org/10.1080/17501229.2019.1608999 


\section{APPENDIX}

\section{Interview Questions}

1. Have you ever studied literature in the language classroom? If yes, describe the lessons and activities.

2. Were the materials and teaching methods you had in your language classes effective and sufficient enough before this class to enable you to achieve your language learning goals?

3. Do you think the use of literature is a good idea to use in language classes?

4. What do you think are the advantages of using literature in the language classroom?

5. What other advantages other than learning English did you gain from the use of literature in language classes?

6. In your view, does the use of literature in language classes develop your linguistic proficiency?

7. What do you think about your participation in discussions?

8. Is there a particular reason that prevented you from engaging in discussions?

9. Do you think the use of literature develops your communicative competence in language classes?

10. How did classroom discussions of literature help you develop your communicative competence?

11. Describe how classroom discussions of literature enabled you to practice the language in meaningful interactions.

12. What do you think are the drawbacks or limitations of using literature in language classes?

13. Do you think the use of literature in language classes can be considered successful?

14. What were the hardest and the easiest aspect of classroom discussions of literature?

15. Do you think this experience will help you control over your own learning? 